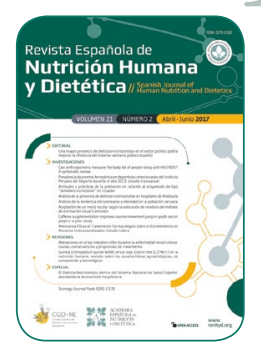

\title{
REVISIÓN
}

\section{Quinoa (Chenopodium quinoa Willd.) versus soja (Glycine max [L.] Merr.) en la nutrición humana: revisión sobre las características agroecológicas, de composición y tecnológicas}

\section{Diana Maria Chito Trujillo ${ }^{\mathrm{a}, *}$, Rubén Andrés Ortega Bonilla ${ }^{\mathrm{b}}$, Andrés Felipe Ahumada Mamián ${ }^{\mathrm{a}}$, Brandón Rosero López ${ }^{a}$}

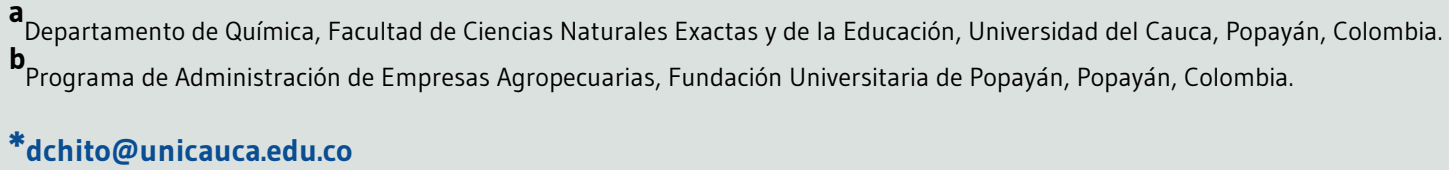

Recibido el 26 de junio de 2016; aceptado el 18 de septiembre de 2016; publicado el 26 de junio de 2017.

\section{PALABRAS CLAVE}

Chenopodium quinoa;

Soja;

Química;

Agricultura;

Digestión.
Quinoa (Chenopodium quinoa Willd.) versus soja (Glycine max [L.] Merr.) en la nutrición humana: revisión sobre las características agroecológicas, de composición y tecnológicas

\section{RESUMEN}

El diseño de alimentos funcionales a partir de productos vegetales muy estudiados como la soja (Glycine max [L.] Merr.) y la potencialización de productos ancestrales como la quinoa (Chenopodium quinoa Willd.) son estrategias factibles para contrarrestar la desnutrición mundial. El objetivo de la presente revisión es describir las características agroecológicas, de composición, nutricionales y tecnológicas de estas dos especies vegetales diferentes (leguminosa y pseudocereal), basado en las publicaciones previas. Se realizó una revisión en bases de datos (Scopus, Web of Science, Scielo) y se complementó con una búsqueda manual en Google Scholar y páginas web de instituciones acreditadas. Los estudios incluidos ( $n=117)$ en esta revisión muestran que la soja se adapta mejor a altitudes bajas $(\sim 1.000 \mathrm{~m} \mathrm{~s}$. $\mathrm{n}$. m.), mientras que la quinoa lo hace en un rango de mayores altitudes $(500-4.000 \mathrm{~m} \mathrm{s.} \mathrm{n.} \mathrm{m.)} \mathrm{con} \mathrm{mayor} \mathrm{tolerancia} \mathrm{a} \mathrm{heladas.} \mathrm{Ambas} \mathrm{son} \mathrm{fuente}$ de una alta calidad proteica por suplir los requerimientos de aminoácidos esenciales sugeridos para niños y adultos sin diferencias significativas $(p>0,05)$, particularmente triptófano y lisina y por los altos porcentajes de digestibilidad $(>70 \%)$. Sus concentraciones bajas de prolaminas y aceptables de $\mathrm{Fe}, \mathrm{Zn}, \mathrm{Ca}$, daidzeína y genisteína los convierten en productos de interés para la industria alimentaria. 


\section{KEYWORDS}

Chenopodium quinoa;

Soybeans;

Chemistry;

Agriculture;

Digestion.
Quinoa (Chenopodium quinoa Willd.) versus soybean (Glycine max [L.] Merr.) in human nutrition: review on agroecological, compositional and technological characteristics

\section{ABSTRACT}

The design of functional foods from well-known vegetables products such as soybean (Glycine $\max$ [L.] Merr.) and the enhancement of ancestral products like quinoa (Chenopodium quinoa Willd.) are feasible strategies to combat worldwide malnutrition. The aim of this review is to describe the agroecological, compositional, nutritional and technological features of these two different vegetable species (leguminous and pseudo-cereal) based on prior publications. In order to reach this goal, a review was performed using databases (Scopus, Web of Science, Scielo) and complemented with a subsequent manual search on Google Scholar and websites of recognized institutions. The included studies $(n=117)$ in this review show that soybean adapts better to low altitudes $(\sim 1,000 \mathrm{~m}$ a. s. I.), while quinoa does it in a range of higher altitudes $(500-4,000 \mathrm{~m}$ a. s. I.) with a high tolerance to frost. Both are a source of high quality proteic given that supply the suggested requirements of essential aminoacids for children and adults with no significant differences, particularly tryptophan and lysine, and due to the high percentages of digestibility $(>70 \%)$. Their low concentrations of prolamins and reasonable levels of $\mathrm{Fe}, \mathrm{Zn}, \mathrm{Ca}$, daidzein and genistein make of them interesting products for food industry.

\section{CITA}

Chito Trujillo DM, Ortega Bonilla RA, Ahumada Mamián AF, Rosero López B. Quinoa (Chenopodium quinoa Willd.) versus soja (Glycine max [L.] Merr.) en la nutrición humana: revisión sobre las características agroecológicas, de composición y tecnológicas. Rev Esp Nutr Hum Diet. 2017; 21(2): 184-98. doi: 10.14306/renhyd.21.2.256

\section{INTRODUCCIÓN}

En los últimos 30 años, la sustitución de las proteínas animales por las vegetales ha ganado popularidad, principalmente por el fortalecimiento que ha tenido la implementación de prácticas de desarrollo sostenible y de estrategias nutricionales promovidas por las organizaciones públicas como consecuencia del rápido crecimiento de la población mundial ${ }^{1}$. Las semillas de quinoa, Chenopodium quinoa Willd., y soja, Glycine max (L.) Merr., son ricas fuentes de proteínas vegetales que desde hace miles de años están presentes en las dietas de las culturas andina y oriental, respectivamente. Su variada composición ha permitido el desarrollo de alimentos funcionales especialmente beneficiosos para la población de países en desarrollo con prevalencia de malnutrición proteico-energética ${ }^{2}$. La quinoa es un pseudocereal autóctono de la región de los Andes en Sudamérica, con centro de origen en Perú y Bolivia ${ }^{2}$. Debido a sus condiciones agroecológicas su cultivo se extendió hacia Colombia, Ecuador y Chile antes de la conquista española 3 . Sin embargo, este histórico evento introdujo cereales como la cebada y el trigo, marginando el cultivo de la quinoa y haciéndolo pasar desapercibido entre los pobladores urbanos por muchos años ${ }^{2}$.

Por otra parte, la soja es la leguminosa cultivada por tradición desde hace más de 3.000 años en China y otros países asiáticos, y más recientemente en los occidentales de zonas templadas y tropicales ${ }^{4}$. Desde 1930, el Departamento de Agricultura de los Estados Unidos inició el desarrollo del cultivo de grano de soja y actualmente este país es el mayor productor seguido por Brasil, Argentina, China e India ${ }^{5}$.

Desde la perspectiva de la nutrición humana, la Organización de las Naciones Unidas para la Alimentación y la Agricultura (FAO) ha dirigido sus esfuerzos a la promoción de estrategias para la mejora del estado nutricional de las poblaciones ${ }^{6}$. Los alimentos se han establecido como el único medio sostenible para alcanzar este objetivo. En este contexto, existe una necesidad global de identificar cultivos con potencial para la producción de alimentos nuevos de calidad $y$ de promover aquellos que favorezcan una sinergia entre

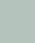


la agricultura y el sector rural ${ }^{7}$. Los cultivos de quinoa y soja en los dos últimos decenios se han catalogado por la FAO como cultivos promisorios de la humanidad para contribuir a la seguridad alimentaria por su calidad nutritiva, variabilidad genética, adaptabilidad y costo de producción. Aunque la masificación del cultivo de soja en Sudamérica cuenta con un mayor tiempo de trayectoria que la quinoa, los retos de desarrollo del nuevo milenio en lo referido a la nutrición humana, involucran la recuperación y reinserción de materias primas marginadas con altas bondades nutritivas y bajo costo como la quinoa². En este contexto, el objetivo de esta revisión es mostrar las características agrícolas, químicas, de procesado y producción más relevantes de las semillas de quinoa, Chenopodium quinoa Willd., y soja, Glycine max (L.) Merr., reportadas en la literatura y proporcionar un análisis comparativo de su valor nutricional que pueda resultar útil a la hora de discernir su utilización en programas de mejora nutricional.

\section{MATERIAL Y MÉTODOS}

Las especies objetos de investigación fueron Chenopodium quinoa Willd. y Glycine max (L.) Merr. Esta revisión se basó en las referencias bibliográficas encontradas en SciELO, Web of Science y Scopus. Se efectuó una búsqueda de los estudios publicados entre 2010 y abril de 2016. Se seleccionaron sólo aquellos artículos publicados en español o inglés. La estrategia de búsqueda se basó en las palabras clave "quinua/soya» o "Chenopodium quinoa/Glycine max» («quinoa/soyabean», en inglés) en combinación con palabras clave relacionadas con «composición nutricional» y «cultivares» como proteínas, carbohidratos, lípidos, factores antinutricionales, procesamiento, compuestos bioactivos, variedades, cultivo, crecimiento (protein, carbohydrates, lipids, antinutritional factors, proccessing, bioactive compounds, varieties, crop, growth) y «revisión o artículo» fue definido como tipo de documento. La revisión bibliográfica se completó con una búsqueda manual de las referencias de las revisiones identificadas (entre 1990 y 2016) en la estrategia de búsqueda utilizando Google Scholar y páginas web de instituciones acreditadas. Las referencias resultantes incluyeron artículos de investigación, trabajos de revisión, libros y reportes. Se excluyeron trabajos de tesis. En caso de encontrar artículos con información repetida, se incluyó aquel que presentó la información más detallada o el más reciente. De entre los estudios localizados, sólo se seleccionaron aquellos que cumplieron con los siguientes criterios: a) artículos con texto completo; b) estudios realizados específicamente con las semillas; c) estudios que registraban todos los parámetros de un análisis proximal; d) estudios que especificaban las concentraciones de los componentes químicos de las especies claramente o en su defecto contemplaban la información necesaria para deducirlo; e) utilización de artículos de investigación para soportar sus resultados; f) utilización de técnicas analíticas validadas y

Figura 1. Diagrama de flujo de la búsqueda bibliográfica y extracción de la información.

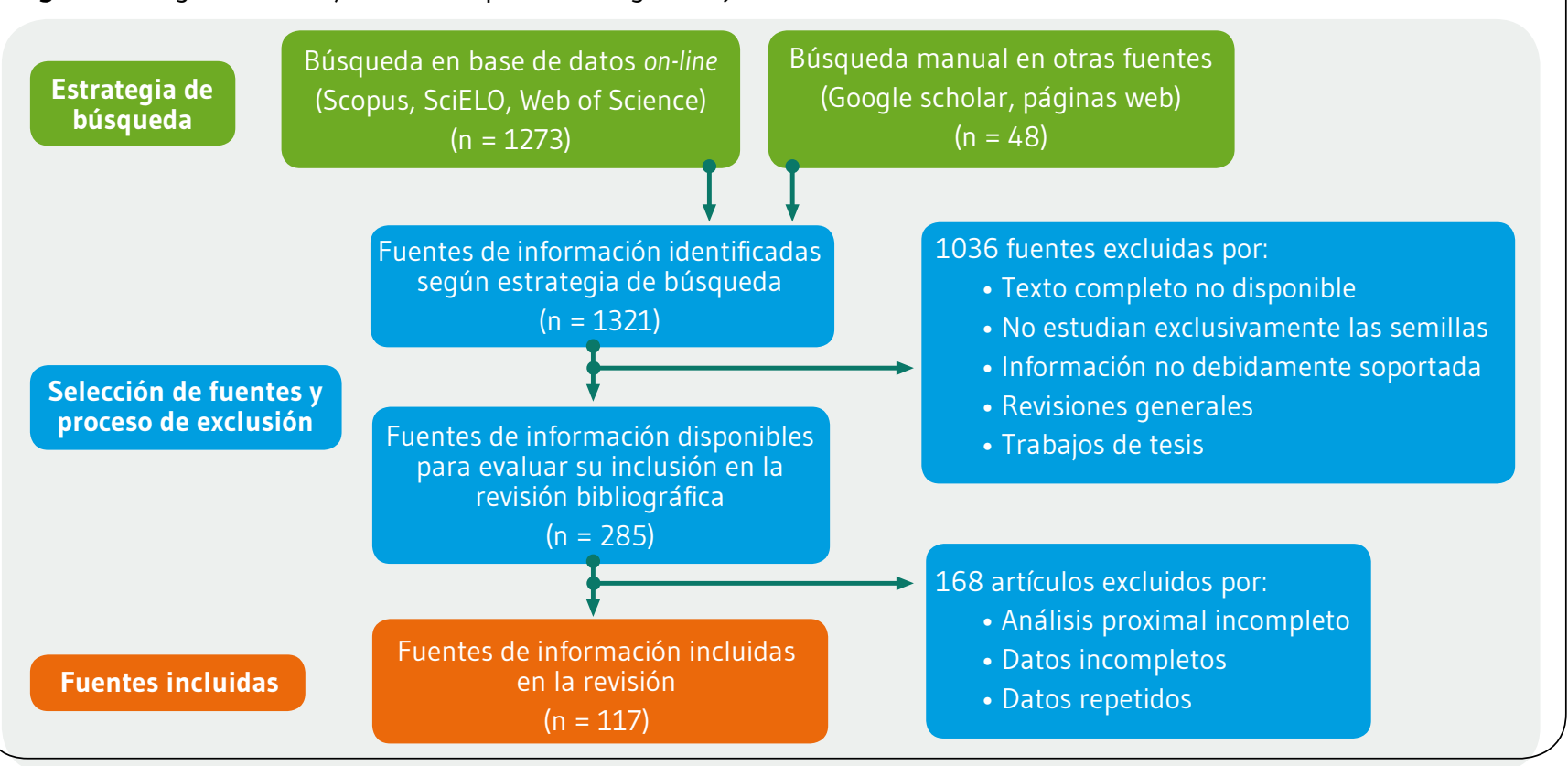


claramente expuestas. En la Figura 1 se puede observar el diagrama de flujo seguido para la selección final de las fuentes de información consideradas. Se seleccionaron las medidas de los parámetros de composición, agroecológicos y de producción reportadas para las especies estudiadas. Se comparó la producción, composición, digestibilidad de aminoácidos, factores antinutricionales y productos derivados que estas especies ofrecen para favorecer la nutrición humana.

Para los cálculos estadísticos se utilizó el software SPSS versión 20. Se aplicó la prueba de U-Mann Whitney para comparar la composición de aminoácidos, vitaminas y minerales en soja y quinoa a un nivel de significancia de $p<0,05$ dado que este es un análisis de muestras independientes con distinto tamaño y distribución no normal.

\section{RESULTADOS Y DISCUSIÓN}

\section{Condiciones de cultivo y rendimientos}

Los cultivos de soja y quinoa constituyen uno de los renglones estratégicos de la seguridad alimentaria y de los ejes económicos en desarrollo para los pobladores de zonas rurales de diversos países de América Latina ${ }^{8-10}$; por lo tanto, es pertinente identificar los factores que pueden incidir negativamente en su productividad. Para una producción competitiva y sostenible, un agroecosistema por excelencia debe garantizar, en términos generales, cosechas en ciclos cortos, factores climáticos y de las plantas apropiadas, alta tolerancia a enfermedades, suelos altamente fértiles, disponibilidad de nutrientes y una óptima irrigación de agua. Ambos cultivos han respondido a diferentes condiciones ecológicas siendo los factores diferenciadores en los rendimientos de producción: la altitud, salinidad, temperatura mínima de germinación, tiempo de cosecha y densidad de siembra.

El cultivo de quinoa se ha desarrollado en un rango amplio de altitudes, menores a $500 \mathrm{~m}$ s. n. m. y hasta $4.000 \mathrm{~m} \mathrm{s.} \mathrm{n.} \mathrm{m.}{ }^{11-18}$ generando mejores rendimientos a alturas entre 2.000 y $3.300 \mathrm{~m} \mathrm{s.} \mathrm{n.} \mathrm{m.;} \mathrm{mientras} \mathrm{que} \mathrm{el} \mathrm{de} \mathrm{soja} \mathrm{a} \mathrm{altitudes} \mathrm{menores}$ a 1.000m s. n. m. ${ }^{19-21}$, lográndose adaptación de la especie en zonas muy tropicales con altitudes menores a $50 \mathrm{~m} \mathrm{s.} \mathrm{n}$. m. ${ }^{22,23}$ y sobre plantas de cobertura a una altitud de $823 \mathrm{~m}$ s. n. m. ${ }^{24}$. Suelos franco o franco arcillosos se reportan como los tipos de suelo adecuados para el crecimiento del cultivo de quinoa ${ }^{14,16}$, y los oxisoles arcillosos para el de soja $a^{21,24}$. Condiciones ligeramente ácidas en los suelos ( $\mathrm{pH}$ alrededor de 6,0 ) han sido tolerados por ambas semillas $20,25,26$.
Un factor que amenaza crecientemente la productividad del grano en los cultivos por el impacto negativo que puede causar en la morfología, fisiología, bioquímica, etc., es la salinidad del suelo con especial predominancia en ambientes áridos o semiáridos. Su incidencia depende de la etapa de crecimiento, nutrición o irrigación. La quinoa ha mostrado una plasticidad para la tolerancia y/o resistencia al incremento del estrés salino y a la disminución de la disponibilidad del agua mayor que la soja ${ }^{27}$. La quinoa ha permitido mayores niveles de salinidad (solución salina con conductividad eléctrica máximo $52 \mathrm{dS} / \mathrm{m}$ para quinoa ${ }^{28}$ frente a $8,0 \mathrm{dS} / \mathrm{m}$ para soja ${ }^{29}$ ), ocasionando un bajo impacto en los rendimientos del grano ${ }^{19,30-32}$, a diferencia de la significativa reducción que se ha observado en los granos de soja debido a la disminución del contenido de clorofila y de la actividad del fotosistema II3 $^{33}$. El favorable comportamiento de la quinoa ha sido explicado a través de la respuesta de sus estomas al cierre y del eficiente sistema que posee para realizar ajustes osmóticos importantes para el mantenimiento de la turgencia de la hoja que la muestran insensible a las sequías y a cambios abruptos de salinidad. Sin embargo, los mecanismos implicados en su flexibilidad fenológica no se han identificado plenamente ${ }^{34}$.

Un aspecto climático diferenciador entre la productividad de las especies de análisis es la tolerancia a las heladas. La severidad del daño depende de la etapa de crecimiento en la que se presente, la temperatura mínima alcanzada y su tiempo de duración. La quinoa ha demostrado tener una capacidad de enfriamiento de $5{ }^{\circ} \mathrm{C}^{16}$ mientras que la soja de $7{ }^{\circ} \mathrm{C}^{20}$ y han sobrevivido hasta temperaturas de $-8{ }^{\circ} \mathrm{C}^{35} \mathrm{y}$ $-4,5^{\circ} \mathrm{C}^{36}$, respectivamente. El fenómeno de las heladas ha generado una reducción en el rendimiento de las semillas de quinoa y soja de hasta un $50 \%$ y representan un mayor riesgo en la parte final (después de la floración) de la época de crecimiento que al inicio. Jacobsen y Cols. ${ }^{37}$ indicaron que el principal mecanismo de supervivencia de la planta de quinoa a las heladas es su capacidad para evitar la formación de hielos en los tejidos tisulares. Experimentos a diferentes altitudes mostraron tolerancia a una misma temperatura de $-8{ }^{\circ} \mathrm{C}$ a distintos tiempos: 4 horas a 3.800 m s. n. m. y 2 horas a altitudes entre 2.500 y $3.000 m$ s. n. m. Estas variaciones son asociadas al contenido de azúcares solubles, prolina y proteína los cuales incrementan el nivel de solutos que protegen y soportan las estructuras celulares bajo estas condiciones.

Ambos cultivos son rotativos, pero la soja tiene ciclos más cortos de maduración (alrededor de 4 meses) que la quinoa (entre 4 y 8 meses de acuerdo a la altitud de la zona de cultivo $\left.{ }^{14,15}\right)$. La siembra de las plantas se lleva a cabo en hileras 
o surcos con densidades de siembra que pueden variar de acuerdo a la región, oscilando alrededor de 200.000 plantas/ha y están separadas a distancias típicas distintas: la soja entre 50 y $80 \mathrm{~cm}^{20,38}$ y la quinoa entre 40 y $60 \mathrm{~cm}^{11,16,39}$. No obstante, las especies han respondido a distancias más estrechas y a mayores densidades reflejándose variaciones en la altura de la planta, en la duración de las etapas de crecimiento y en los rendimientos de materia seca de las plantas y de los granos.

La viabilidad económica de los sistemas de producción agronómica se asocia principalmente con el rendimiento de los granos. Según Mujica y Cols. ${ }^{40}$, el rendimiento es el resultado de las componentes de tipo genético, ambiental y la interacción genético-ambiental, donde la parte genética es importante desde el punto de vista del mejoramiento. Los estudios disponibles no muestran modificaciones transgénicas en las semillas de quinoa. La literatura reporta mayores densidades de siembra para soja que para quinoa y, a su vez, mayores rendimientos de grano. Rendimientos de grano de soja entre 2.500 y $3.000 \mathrm{~kg} /$ ha se reportan para densidades de siembra entre 200.000 y 350.000 plantas/ha20,41; mientras que las densidades de siembra para quinoa oscilan alrededor de 200.000 plantas/ha y generan rendimientos de semillas entre 1.700 y $2.400 \mathrm{~kg} / \mathrm{ha}^{11,39}$.

\section{Composición}

Proteínas: La soja es la leguminosa más rica en proteína consumida en todo el mundo $3,23,25,42,43$. Su contenido es aproximadamente el doble (>36\%) del encontrado en quinoa (entre $8 \%$ y $24 \% 3,15,16,25,44,45$ ).

Las proteínas de las semillas están principalmente en forma de proteína almacenada, no tienen actividad enzimática y simplemente son una fuente de aminoácidos, nitrógeno y carbono para el desarrollo de las plantas. Están depositadas en forma insoluble en cuerpos proteicos, se clasifican de acuerdo a su solubilidad, y sobreviven a procesos de desecación por tiempos prolongados. En las semillas de quinoay soja, lasalbúminasylas globulinas son los principales grupos de proteínas de almacenamiento que conforman la fracción proteica (44-77\%), siendo chenopodina la principal globulina en la quinoa ${ }^{46}$ y la glicinina y $\beta$-conglicinina, las dos subunidades de globulinas mayoritarias en el grano de soja $(70 \%)^{43}$. Dado los bajos porcentajes de prolaminas $(\leq 7 \%)^{3}$, la soja y la quinoa se clasifican como granos libres de gluten y alimentos de especial interés para las personas que muestran intolerancia al gluten. Diversos autores han encontrado valores moderados de ácido glutámico y glutamina ( 23 y $27 \%$, respectivamente), y valores mínimos de prolina (0 y $3 \%$, respectivamente $)^{47,48}$. Además, la quinoa se promueve como un sustituto del arroz en alimentación para niños debido a su baja alergenicidad ${ }^{49}$. Zevallos y Cols. ${ }^{50}$ mostraron que pacientes celíacos pueden tolerar una ingesta diaria de $50 \mathrm{~g}$ de quinoa durante 6 semanas.

El aspecto más importante de las proteínas presentes en estos productos alimenticios, desde el punto de vista nutricional, es su aporte de aminoácidos, especialmente los esenciales que son los incorporados a través de la dieta e indispensables para el desarrollo y mantenimiento de diversas necesidades metabólicas. La Tabla 1 reúne las medias para estos aminoácidos esenciales calculadas a partir de las mediciones reportadas por distintas fuentes para diferentes variedades de granos de soja y quinoa. Se observa que no existen diferencias significativas $(p>0,05)$ entre los niveles reportados para los aminoácidos esenciales de estas especies. Los requerimientos sugeridos por la FAO para niños, adolescentes y adultos son cubiertos por el pseudocereal y la leguminosa supliendo alrededor del $163 \%$ de la histidina, el $114 \%$ de la lisina y el $142 \%$ de la metionina + cisteína, confirmando el alto valor biológico del contenido proteico. Según Kozioł ${ }^{3}$, las altas concentraciones de lisina, histidina, metionina + cisteína e isoleucina, así como los bajos niveles de triptófano, están directamente relacionadas con las altas concentraciones de las fracciones de albúminas y globulinas en las semillas. Es de resaltar, además, el gran valor nutricional que supone garantizar los requerimientos de estos diez aminoácidos, puesto que por la limitación de uno sólo, se produce descomposición y eliminación de los restantes, provocando pérdidas de nitrógeno en la dieta. Las cantidades máximas de lisina en ambas especies superan valores reportados para otros alimentos de origen vegetal incorporados diariamente en dietas latinoamericanas como el maíz, trigo, judías ${ }^{3}$ y el arroz ${ }^{51}$, complementando además, sus particulares bajos niveles de metionina e histidina.

Tabla 1. Comparación de los perfiles de aminoácidos esenciales reportados para los granos de quinoa y soja, y los patrones de los requerimientos para niños, adolescentes y adultos sugeridos (g/100 g proteína).

\begin{tabular}{|c|c|c|c|c|c|c|}
\hline \multirow{2}{*}{ Aminoácido esencial } & \multicolumn{3}{|c|}{$\begin{array}{l}\text { Tipo de grano } \\
\text { Promedio, mín.-máx. }(n)\end{array}$} & \multicolumn{3}{|c|}{ Patrón FAO/OMS ${ }^{£}$ (años) } \\
\hline & Quinoa $^{\ddagger}$ & Soja $a^{\S}$ & ${ }^{*} p$-valor & $(0,5-10)$ & (11-18) & $(>18)$ \\
\hline His & $\begin{array}{c}2,7 \\
1,4-5,40(n=41)\end{array}$ & $\begin{array}{c}2,5 \\
2,3-2,6(n=4)\end{array}$ & 0,157 & 1,8 & 1,6 & 1,5 \\
\hline
\end{tabular}


Quinoa (Chenopodium quinoa Willd.) versus soja (G/ycine max [L.] Merr.) en la nutrición humana: revisión sobre las características agroecológicas, de composición y tecnológicas

\begin{tabular}{|c|c|c|c|c|c|c|}
\hline \multirow{2}{*}{ Aminoácido esencial } & \multicolumn{3}{|c|}{$\begin{array}{l}\text { Tipo de grano } \\
\text { Promedio, mín.-máx. }(n)\end{array}$} & \multicolumn{3}{|c|}{ Patrón FAO/OMS ${ }^{£}$ (años) } \\
\hline & Quinoa $^{\ddagger}$ & Soja ${ }^{5}$ & $* p$-valor & $(0,5-10)$ & (11-18) & $(>18)$ \\
\hline Ile & $\begin{array}{c}3,1 \\
0,8-7,4(n=42)\end{array}$ & $\begin{array}{c}4,4 \\
4,0-4,6(n=5)\end{array}$ & 0,137 & 3,1 & 3,0 & 3,0 \\
\hline Leu & $\begin{array}{c}6,0 \\
2,3-9,4(n=42)\end{array}$ & $\begin{array}{c}7,8 \\
7,7-7,9(n=5)\end{array}$ & 0,143 & 6,3 & 6,1 & 5,9 \\
\hline Lys & $\begin{array}{c}4,8 \\
2,4-7,8(n=42)\end{array}$ & $\begin{array}{c}6,2 \\
5,2-6,4(n=5)\end{array}$ & 0,141 & 5,2 & 4,8 & 4,5 \\
\hline Met & $\begin{array}{c}1,9 \\
0,3-9,1(n=41)\end{array}$ & $\begin{array}{c}1,8 \\
1,2-3,0(n=4)\end{array}$ & 0,480 & \multirow{2}{*}{2,5} & \multirow{2}{*}{2,3} & \multirow{2}{*}{2,2} \\
\hline Cys & $\begin{array}{c}1,4 \\
0,1-2,7(n=11)\end{array}$ & $\begin{array}{c}1,5 \\
1,3-1,8(n=4)\end{array}$ & 0,460 & & & \\
\hline Phe + Tyr & $\begin{array}{c}6,3 \\
2,7-10,3(n=41)\end{array}$ & $\begin{array}{c}8,0 \\
6,1-9,3(n=5)\end{array}$ & 0,380 & 4,6 & 4,1 & 3,8 \\
\hline Thr & $\begin{array}{c}3,7 \\
2,1-8,9(n=42)\end{array}$ & $\begin{array}{c}3,9 \\
3,5-4,5(n=5)\end{array}$ & 0,770 & 2,8 & 2,5 & 2,3 \\
\hline $\operatorname{Trp}$ & $\begin{array}{c}0,9 \\
0,6-1,9(n=27)\end{array}$ & $\begin{array}{c}2,1 \\
0,7-3,4(n=5)\end{array}$ & 0,383 & 0,7 & 0,6 & 0,6 \\
\hline Val & $\begin{array}{c}3,7 \\
0,8-6,1(n=42)\end{array}$ & $\begin{array}{c}4,5 \\
4,3-4,8(n=5)\end{array}$ & 0,146 & 4,1 & 4,0 & 3,9 \\
\hline
\end{tabular}

$\boldsymbol{n}$ : número de datos.

${ }^{\ddagger}$ Valores reportados por Nowak y Cols. ${ }^{44}$.

sValores derivados de los siguientes artículos: Ahamed y Cols. ${ }^{52}$, Berk ${ }^{53}$, Bhat y Col. ${ }^{54}$, Carrera y Cols. ${ }^{55}$, Vasconcelos y Cols. ${ }^{23}$.

EValores adaptados de FAO/OMS ${ }^{56}$.

${ }^{*} \boldsymbol{p}<0,05$.

His: histidina; Ile: isoleucina; Leu: leucina; Lys: lisina; Met: metionina; Cys: cisteína; Phe+Tyr: fenilalanina + tirosina; Thr: treonina; Trp: triptófano; Val: valina.

Para complementar el entendimiento de la calidad de las proteínas contenidas en los granos de quinoa y soja, se deben contrastar también los niveles de digestibilidad o absorción final de los aminoácidos constituyentes que posteriormente pueden pasan a la sangre y alcanzar los diferentes tejidos. Los rangos de digestibilidad reportados para estas proteínas de origen vegetal son de $79-91 \%$ y $71-85 \%$, para quinoa y soja, respectivamente ${ }^{51,57-60}$. Estas ligeras diferencias se pueden acentuar con los tratamientos de procesado convencionales (molienda, cocción, etc.) o con el contenido de factores antinutricionales ${ }^{61}$.

Carbohidratos: En términos generales, los carbohidratos hacen parte de los componentes mayoritarios de los granos de quinoa y soja. En la composición de la quinoa figuran como el componente principal, con un porcentaje de 56$74 \%$ en materia seca $3,25,44,45,62,63$. Para la soja, el contenido se reduce a valores por debajo de la mitad, 14-40\% $3,23,64$, situándolo como el segundo constituyente del grano. El almidón es el polisacárido de reserva más importante en la quinoa, representa alrededor de un $60 \%$ y en la soja solamente entre 2 y $4 \% 23,65$. Además, se ha reportado que los gránulos de almidón de la quinoa con forma poligonal tienen un diámetro particularmente mucho más pequeño $(<3,0 \mu \mathrm{m})$ que los encontrados en forma esférica para otros granos como el trigo (hasta $40 \mu \mathrm{m}$ ) o el maíz (hasta $23 \mu \mathrm{m}$ ) 3,25. Esta es una característica ventajosa, frente a los granos de soja, que se asocia a una temperatura de gelatinización más alta y a una mayor viscosidad que las detectadas para otros granos ${ }^{66}$. Así mismo, esta propiedad promueve a la quinoa como un producto de alto potencial en la industria alimentaria para la obtención de películas biodegradables o como aditivo alimentario en preparaciones que requieran resistencia a la retro-degradación. 
Por otra parte, ambos granos son fuentes de altos contenidos de fibra dietética, y esta característica permite incluirlos en la categoría de alimentos funcionales, puesto que su uso dentro de una dieta balanceada puede reducir el riesgo de algunas enfermedades como las coronarias y el cáncer ${ }^{23,64,67}$. El porcentaje de fibra dietética total para la quinoa varía entre 9,3 y $13,5 \%^{15,31,44,68}$ y para la soja entre 11 y 19\% ${ }^{23,64,67}$.

Otros carbohidratos presentes en menores proporciones en los granos de quinoa y soja son la glucosa, fructosa, arabinosa, galactosa, sacarosa, maltosa y rafinosa ${ }^{25,62,66}$.

Lípidos: El contenido de grasa encontrado en el grano de quinoa varía entre 2 y $10 \%$ de materia seca $3,44,63,66,69$ y se encuentra por debajo del rango reportado para el grano de soja, entre 14 y $24 \%{ }^{23,64}$. Las dos especies reportan una composición similar de ácidos grasos insaturados posicionándolos como fuentes adecuadas de aceites vegetales comestibles que suplen los ácidos grasos esenciales a través de la dieta. Predomina el alto porcentaje de omega- 6 (ácido linoleico, C18:2n6) con valores de $55 \%$ para soja y $47-56 \%$ para quinoa; omega-3 (ácido $\gamma$-linolénico, C18:3n6) con porcentajes de $9,4 \%$ para soja y $4-9 \%$ para quinoa, y omega-9 (ácido oleico, C18:1n9) con valores muy cercanos, 21\% para soja y $22-29 \%$ para quinoa ${ }^{3,44,69,70}$. Ácidos poliinsaturados del tipo eicosanoicos, docosanoicos y tetracosanoicos se han detectado en menor proporción solamente en quinoa. De otra parte, los ácidos palmítico (C16:0) y esteárico (C18:0) son los ácidos grasos saturados mayoritarios en los granos, representando un mayor porcentaje en el contenido total de grasa para los granos de soja $(\sim 14 \%)^{3,69}$. La estabilidad de estos ácidos insaturados frente a procesos de rancidez oxidativa es preservada por la acción antioxidante que proporcionan especies lipídicas como los $\alpha, \beta, \gamma, \delta$-tocoferoles $y$ $\alpha, \beta, \gamma, \delta$-tocotrienoles presentes en las semillas de quinoa y soja, los cuales se conocen en conjunto como vitamina $E$. El $\alpha$-tocoferol es el homólogo al que se le confiere mayor capacidad antioxidante ${ }^{71}$. Análisis de semillas de quinoa y soja muestran niveles de $\alpha$-tocoferol de $8-53 p^{25 m^{25,63,69,70} y}$ $26 \mathrm{ppm}^{72}$, respectivamente; mientras que en los aceites extraídos los niveles encontrados están entre 251 y $754 \mathrm{ppm}$ para el aceite de quinoa ${ }^{3,66}$, y 80-121ppm para el de soja ${ }^{3,73}$. Aunque los tocotrienoles también han mostrado actividad antioxidante, las concentraciones encontradas son mucho más bajas ${ }^{69,72}$.

Vitaminas y minerales: La información sobre los elementos traza contenidos en los granos de quinoa y soja supone gran importancia a la hora de valorar alimentos que permitan favorecer el estado nutricional de poblaciones con mayor susceptibilidad a mostrar signos de malnutrición por deficiencia de micronutrientes, particularmente en zonas rurales ${ }^{74,75}$. La Tabla 2 muestra la comparación de las concentraciones de vitaminas $A$, grupo $B, C, K$ y E y elementos traza contenidas en granos de diversas variedades de quinoa y soja. Los niveles de vitamina $E$ en la quinoa resultan significativamente más altos que los reportados para la soja $(p=0,040)$. Se detectan diferencias no significativas entre los valores medios descritos para las vitaminas tiamina, riboflavina, niacina y $C$ en las semillas $(p>0,05)$.

Tabla 2. Composición de vitaminas y minerales reportada para los granos de quinoa y soja expresados como mg/100 g materia seca.

\begin{tabular}{|c|c|c|c|}
\hline \multirow{2}{*}{ Vitaminas y minerales } & \multicolumn{3}{|c|}{$\begin{array}{l}\text { Tipo de grano } \\
\text { Promedio, mín.-máx. ( } n)\end{array}$} \\
\hline & Quinoa $^{\ddagger}$ & Sojas & ${ }^{*} p$-valor \\
\hline $\mathrm{A}$ (mg RE/100 g) & $0,20(n=1)$ & $0,11(n=1)$ & - \\
\hline Tiamina & $\begin{array}{c}0,43 \\
0,20-0,65(n=10)\end{array}$ & $\begin{array}{c}0,61 \\
0,05-0,91(n=3)\end{array}$ & 0,398 \\
\hline Riboflavina & $\begin{array}{c}0,16 \\
0,06-0,39(n=10)\end{array}$ & $\begin{array}{c}0,44 \\
0,13-0,87(n=3)\end{array}$ & 0,128 \\
\hline Niacina & $\begin{array}{c}1,07 \\
0,50-1,57(n=10)\end{array}$ & $\begin{array}{c}1,89 \\
1,62-2,19(n=2)\end{array}$ & 0,032 \\
\hline Ácido Pantoténico & $N R$ & $0,79(n=1)$ & - \\
\hline $\mathrm{B}_{6}$ & NR & $\begin{array}{c}0,56 \\
0,38-0,78(n=3)\end{array}$ & - \\
\hline
\end{tabular}




\begin{tabular}{|c|c|c|c|}
\hline \multirow{2}{*}{ Vitaminas y minerales } & \multicolumn{3}{|c|}{$\begin{array}{l}\text { Tipo de grano } \\
\text { Promedio, mín.-máx. }(n)\end{array}$} \\
\hline & Quinoał & Sojas & ${ }^{*} p$-valor \\
\hline Ácido Fólico & $0,08(n=1)$ & $0,19(n=1)$ & - \\
\hline C & $\begin{array}{c}14,96 \\
4,00-23,07(n=8)\end{array}$ & $\begin{array}{c}7,98 \\
6,00-9,96(n=2)\end{array}$ & 0,117 \\
\hline $\mathrm{K}$ & NR & $0,05(n=1)$ & - \\
\hline E & $\begin{array}{c}3,08 \\
2,45-4,64(n=7)\end{array}$ & $\begin{array}{c}0,47 \\
0,09-0,85(n=2)\end{array}$ & 0,040 \\
\hline Mg & $\begin{array}{c}340,87 \\
150,91-2620,00 \quad(n=19)\end{array}$ & $\begin{array}{c}236,12 \\
1,33-294,80(n=8)\end{array}$ & 0,137 \\
\hline $\mathrm{Fe}$ & $\begin{array}{c}9,96 \\
1,40-81,00(n=23)\end{array}$ & $\begin{array}{c}8,39 \\
4,89-15,70(n=8)\end{array}$ & 0,095 \\
\hline $\mathrm{Ca}$ & $\begin{array}{c}144,70 \\
44,00-874,00(n=19)\end{array}$ & $\begin{array}{c}41,09 \\
0,81-277,00(n=8)\end{array}$ & 0,002 \\
\hline $\mathrm{Na}$ & $\begin{array}{c}17,68 \\
6,00-26,55(n=10)\end{array}$ & $\begin{array}{c}2,19 \\
0,87-3,33(n=8)\end{array}$ & 0,000 \\
\hline$P$ & $\begin{array}{c}652,99 \\
140,00-5350,00(n=18)\end{array}$ & $\begin{array}{c}704,00(n=1) \\
9,12\end{array}$ & 0,144 \\
\hline $\mathrm{Cu}$ & $\begin{array}{c}1,93 \\
0,20-10,00(n=19)\end{array}$ & $\begin{array}{c}1,14-14,33(n=8) \\
26,60\end{array}$ & 0,000 \\
\hline Zn & $\begin{array}{c}5,58 \\
2,15-36,00(n=17)\end{array}$ & $\begin{array}{c}2,39-40,98(n=8) \\
929,88\end{array}$ & 0,009 \\
\hline K & $\begin{array}{c}1366,44 \\
649,00-2325,56(n=15)\end{array}$ & $\begin{array}{c}2,07-1797,00(n=8) \\
2,51\end{array}$ & 0,220 \\
\hline Mn & $\begin{array}{c}7,16 \\
1,95-33,00(n=10)\end{array}$ & $0,67-2,93(n=8)$ & 0,477 \\
\hline
\end{tabular}

n: número de datos. NR: not reported.

${ }^{\ddagger}$ Valores reportados por Vega-Galvez y Cols. ${ }^{15}$, Kozioł ${ }^{3}$, Nowak y Cols. ${ }^{44}$, Miranda y Cols. ${ }^{63}$, Repo-Carrasco y Cols. ${ }^{66}$, Tang y Cols. ${ }^{69}$, Ruales y Col. ${ }^{70}$, Ranhotra y Cols. ${ }^{76}$, Blanco y Cols. ${ }^{77}$, Lazarte y Cols. ${ }^{78}$, Miranda y Cols. ${ }^{79}$, Nascimento y Cols. ${ }^{80}$.

$\S$ Valores derivados de los siguientes artículos: Wang y Cols. ${ }^{64}$, Lebiedzińska y Col. ${ }^{81}$, Plaza y Cols. ${ }^{82}$, Ridner $^{83}$. ${ }^{*} \boldsymbol{p}<0,05$.

Mg: magnesio; Fe: hierro; Ca: calcio; Na: sodio; P: fósforo; Cu: cobre; Zn: zinc; K: potasio; Mn: manganeso.

Teniendo en cuenta los niveles de ingesta requeridos establecidos por la $\mathrm{FAO} / \mathrm{OMS}^{84}$, se estima que los granos podrían ser buenas fuentes de vitaminas $A$, niacina, C y E. Estudios del monitoreo de los niveles de estas vitaminas en los granos, tras los procesos de perlado y lavado que suponen su consumo, resaltan su incremento debido a ligeras variaciones de su peso. Por ejemplo, $100 \mathrm{~g}$ de quinoa comestible alcanzan a suplir un $6 \%$ de niacina ${ }^{3}$. Por otra parte, ingestas adecuadas de $\mathrm{Fe}$, Zn y Ca garantizan un óptimo crecimiento y desarrollo de infantes y niños, y un estado nutricional saludable en general. Particularmente, las concentraciones promedio de Ca y Na muestran a la quinoa como una fuente significativamente mejor de estos minerales $(p<0,05)$, a la soja como un proveedor de concentraciones significativamente mayores de $\mathrm{Zn}$ y $\mathrm{Cu}(\mathrm{p}<0,05)$, y tanto a la quinoa como a la soja como fuentes equivalentes de Fe y de otros minerales como Mg, P, K y Mn. Ensayos han mostrado que $100 \mathrm{~g}$ de porción comestible de quinoa proporcionan $4-6 \%$ del requerimiento diario de $\mathrm{Ca}$, $27-40 \%$ de $\mathrm{Fe}$, y $10-15 \%$ de $\mathrm{Zn}^{3}$. 


\section{Factores benéficos y adversos para la nutrición}

Las dietas de las comunidades que habitan las áreas rurales de países en desarrollo implican una limitada ingesta de alimentos de origen animal. En este contexto, la promoción y fortalecimiento de los cultivos de quinoa y soja, a través de las asociaciones y el cooperativismo, se ha convertido para estas poblaciones en una opción de mejoramiento de su calidad de vida y de sus perfiles nutricionales tanto por los beneficios derivados de su comercialización como por la disponibilidad inmediata para su consumo ${ }^{85,86}$. A estos hechos se aúna la versatilidad gastronómica que ofrecen.

Como se describió previamente, estas semillas son buenas fuentes de minerales pero además se caracterizan por contener especies quelantes como los fitatos, oxalatos y taninos, que forman parte de los factores antinutricionales de estos alimentos. Éstos actúan como inhibidores de la absorción de minerales divalentes en el tracto digestivo, en especial de $\mathrm{Fe}, \mathrm{Ca}$ y $\mathrm{Zn}^{78}$ que están directamente asociados a patologías de malnutrición. El ácido fítico es la principal forma de almacenamiento de fósforo, está presente en las principales partes anatómicas de las semillas (embrión, perispermo, endosperma) en diferentes proporciones siendo el embrión la región que alberga mayores fracciones ${ }^{87}$ y su contenido depende de la variedad del grano. Los niveles de fitatos o ácido fítico reportados para la quinoa están entre 100 y $2.280 \mathrm{mg} / 100 \mathrm{~g}$ para el grano pulido ${ }^{70,78,88}$ y alrededor de $1.000 \mathrm{mg} / 100 \mathrm{~g}$ para grano entero ${ }^{70}$. Para la soja pulida los valores encontrados son muy similares, están entre 100 y $2.890 \mathrm{mg} / 100 \mathrm{~g}^{88-91}$. Sin embargo, la biodisponibilidad de los minerales depende de la concentración libre o virtualmente disponible para el organismo. Diferentes autores han sugerido las proporciones molares fitatos:mineral como un indicador apropiado para estimar la biodisponibilidad de $\mathrm{Fe}$, Ca y $Z \mathrm{n}^{78,88}$. Se espera una adecuada biodisponibilidad de $\mathrm{Zn}$ si la proporción fitatos:Zn es menor a 0,15; de Ca si fitatos:Ca es menor a 0,24; y de Fe si fitatos:Fe es menor a 1,0. El monitoreo de estas relaciones molares en grano y harina de quinoa y soja ha mostrado una fuerte interacción entre el ácido fítico y el $\mathrm{Zn}$ con mayor prevalencia en la quinoa (fitatos:Zn entre 40-212 para quinoa y entre 13-40 para soja). Con respecto al $\mathrm{Fe}$, se ha detectado una muy baja disponibilidad (fitatos:Fe entre 8-17 para quinoa y alrededor de 15 para soja) mientras que se predice una alta disponibilidad del Ca alojado en el grano de quinoa (fitatos: $\mathrm{Ca}=0,1287$ ), en el salvado (fitatos: $\mathrm{Ca}=0,1287$ ) y el grano pulido (fitatos: $\mathrm{Ca}=0,0788$ ), pero no en los granos de soja (fitatos: $\mathrm{Ca}=0,30-0,60^{88,90}$ ). Estos hallazgos indican que el proceso de remoción de la cubierta del grano de quinoa y soja no son suficientes para garantizar una óptima absorción de nutrientes una vez se incorporan en una dieta balanceada. Se requieren tratamientos adicionales que permitan reducir el contenido de fitatos sin alterar significativamente el contenido de minerales. Tradicionalmente, se han involucrado técnicas de procesamiento como la germinación, el remojo o inmersión, la fermentación y tratamientos térmicos con el fin de activar las fitasas endógenas capaces de hidrolizar los fitatos y aumentar la biodisponibilidad de minerales antes de su consumo ${ }^{92}$. El efecto de la temperatura y presión vía microondas, autoclave u olla presión sobre la harina de soja ha mostrado una reducción de casi un $50 \%$ del contenido de fitatos ${ }^{93}$. El proceso de remojo por 12 horas ha permitido una reducción de un 13\%, mientras que la germinación por 72 horas hasta un $65 \%{ }^{90}$. En el caso de la quinoa se ha observado un efecto reductor progresivo de fitatos con el proceso de germinación (35$38 \%)$, remojo (60-80\%), fermentación láctica $(85-88 \%)$ y con la combinación germinación + fermentación (95-98\%) logrando aumentar hasta en 8 veces la disponibilidad del hierro ${ }^{92}$. Estos procesos favorecen la lixiviación de los fitatos al medio y/o favorece las condiciones óptimas de $\mathrm{pH}$ $(4,5-5,0)$ para las fitasas endógenas permitiendo incrementar su actividad catalítica. De hecho, se alcanza una mayor disminución del pH a través de la fermentación. Humer y Schedle. ${ }^{88}$ exponen un aumento de la biodisponibilidad de Fe por implementación de este proceso mayor con quinoa (8 veces) que con soja ( 1,5 veces).

Un factor que limita el uso de la harina de soja y quinoa es su fuerte olor y sabor amargo debido a la actividad de la lipoxigenasa sobre los ácidos grasos poliinsaturados y al contenido de saponinas presentes en las diversas partes de la semilla. Para el caso del grano entero y molido de quinoa se reporta una actividad enzimática de 50,9 unidades $/ \mathrm{g}$ siendo el embrión el lugar donde se concentra. En el salvado la actividad catalítica detectada ha sido nula, por lo que se estima que el proceso de descarado no favorece la reducción del olor. Ensayos de la actividad catalítica de la lipoxigenasa en distintos cultivos de soja reportan valores de densidad óptica por mg de proteína por minuto entre 7,81 y $16,5^{94}$. Con respecto al contenido de saponinas se ha establecido que este predomina en el salvado de la quinoa $\left(2,2 \%{ }^{87}\right)$ siendo la remoción de la cáscara de los granos uno de los procedimientos típicamente usados para reducir el sabor amargo. Se ha estimado que un grado de abrasión de 30\% reduce más de un $50 \%$ del contenido de saponinas en la quinoa cuyo contenido puede oscilar entre 0,1 y $21 \% 15,52,95$. En la soja el contenido total puede oscilar entre 0,62 y $6,16 \%^{52,96}$ El contenido total remanente de saponinas en las semillas de soja ha resultado ser más alto que en quinoa ${ }^{52}$.

Otros antinutrientes presentes en estas semillas son los inhibidores de tripsina los cuales impiden la actividad catalítica de estas enzimas proteolíticas constituyéndose en inhibidores del crecimiento. Además, se encuentran los 
Quinoa (Chenopodium quinoa Willd.) versus soja (G/ycine max [L.] Merr.) en la nutrición humana: revisión sobre las características agroecológicas, de composición y tecnológicas

taninos que son capaces de formar complejos estables con proteínas, enzimas digestivas y lípidos dando lugar a la aglutinación de liposomas. Las unidades de inhibidor de tripsina encontradas en quinoa son mucho más bajas (1,4$5,0 \mathrm{mg})$ que las determinadas en soja $(24,5-41,5 \mathrm{mg})^{52}$. Por otra parte, en la soja se ha detectado un menor porcentaje de taninos $(0,05)$ en comparación con la quinoa $(0,5)$. Una forma de reducir la presencia de estos antinutrientes es a través de abrasión, lavado y/o tratamiento térmico ${ }^{97}$. Estos procedimientos también se constituyen en una manera de reducir la hipertrofia que se puede llegar a observar en el páncreas debido a la continua ingesta de estos productos. Sin embargo, la incorporación de salvado ${ }^{52}$, bebidas o de productos fermentados son alternativas para el consumo de estos alimentos que minimizan estos efectos adversos y al mismo tiempo garantizan la calidad proteica y la biodisponibilidad de minerales a la dieta.

Además de los taninos, los granos de quinoa y soja contienen glucósidos de flavonas, flavonoides y antocianinas (polifenoles) a los cuales se les confiere una potente actividad antioxidante. Las isoflavonas daidzeína y genisteína han mostrado la capacidad de unirse a receptores de estradiol actuando como fitoestrógenos con características estructurales similares al 17- $\beta$-estradiol. Esta cualidad soporta la funcionalidad nutricional que se le atribuye a los granos de quinoa y soja. Ensayos con las dos especies se han enfocado al entendimiento del rol de las isoflavonas sobre la osteoporosis, ateroesclerosis y enfermedades cardiovasculares, pero a la fecha sigue siendo un tema de investigación. Análisis con diversos cultivos de soja y quinoa muestran las semillas de soja como el mayor contribuyente de genisteína $(0,20-0,90 \mathrm{mg} / 100 \mathrm{~g}$ y 0,19-1,12mg/100g de daidzeína) ${ }^{64}$ y a la quinoa de daidzeína $(0,70-2,05 \mathrm{mg} / 100 \mathrm{~g}$ y 0,04-0,41mg/100g de genisteína) ${ }^{98}$. Liggins y Cols. ${ }^{99}$ encontraron además que los niveles de estas dos isoflavonas en la harina de soja $(0,90-1,08 \mathrm{mg} / \mathrm{g}$ de genisteína y 0,7-1,03mg/g de daidzeína) son significativamente superiores a los cuantificados en alimentos consumidos típicamente en Reino Unido como por ejemplo arroz, pasta y otros cereales.

Finalmente, en el marco de la soberanía alimentaria, la quinoa en comparación con la soja ha sido un cultivo que ha mostrado una mayor resistencia a los procesos de mejoramiento genético ${ }^{100,101}$, hecho que desde el punto de vista de la seguridad alimentaria favorece su aceptación por los consumidores. Si bien este aspecto tiene diferentes matices, no se puede olvidar dado que trae consigo implicaciones en la composición y valoración nutricional de las semillas.

\section{Potencial para la industria alimentaria}

La creciente demanda de la población, comprometida con una alimentación saludable, por alimentos que ayuden a prevenir o controlar enfermedades, ha supuesto una oportunidad de diversificación de mercados para la industria alimentaria. La producción de alimentos de base natural visible es una de sus estrategias de innovación más recientes. Para ello, los procesos de investigación industriales se vienen desarrollando en colaboración con las empresas de ingredientes. En este contexto, las supuestas bondades de la soja siguen siendo reconocidas para preparaciones industriales, mientras que la quinoa aparece como un nuevo ingrediente cuya obtención y reconocimiento nutricional se está expandiendo. Sus contenidos de proteínas los potencian como posibles ingredientes de alimentos funcionales con proteínas, que en principio están siendo los más reclamados por los consumidores y por los entes de control de la situación nutricional de la población a nivel mundial ${ }^{102}$.

Otro eje de innovación de la industria de alimentos es el desarrollo de productos tipificados como "libres de", los cuales son diseñados para consumidores con dietas específicas. En este caso, los bajos contenidos de prolaminas presentes en las semillas de quinoa y soja han favorecido su recomendación para dietas bajas en gluten y han promovido procesos de investigación para su acertada inclusión en productos para celíacos, dado que los umbrales a concentración de alérgenos varían entre los consumidores.

Estos alimentos son objeto de estudio tanto para mantener su condición nutricional tras el procesamiento industrial como para reducir los niveles de alérgenos. Entre los tipos de procesamiento que pueden afectar las propiedades alergénicas de estos alimentos están el calentamiento, la fermentación, hidrólisis enzimática y tratamientos físicos como la extrusión, uso de conservantes y cambios de $\mathrm{pH}$ o combinaciones de estos.

El contenido proteico de las semillas de soja incluye 8 proteínas alérgenas (denominadas Gly $\mathrm{m} 1$ a Gly $\mathrm{m} \mathrm{8}$ ) $^{103}$. $\beta$-conglicina y glicinina (Gly $\mathrm{m} 5$ y Gly $\mathrm{m} 6$, respectivamente) son proteínas de almacenamiento asociadas a reacciones alérgicas severas ${ }^{104}$. Ebisawa y Cols. ${ }^{105}$ reportaron altos valores de Gly m 8, una 2S-albúmina, en diagnósticos de niños alérgicos a la soja. Por otra parte, Gly m1 y Gly m 2 no se consideran alérgenos alimentarios. La literatura reporta algunas pruebas de la reducción o retención de la alergenecidad de la soja a través de su procesamiento, pero no hay evidencias de su incremento. Gomaa y Boye ${ }^{106}$ encontraron que el calentamiento de la proteína de soja 
cruda o de algunas fracciones producía una reducción significativa de la capacidad enlazante de lgE a través de ensayos de ELISA con suero de niños. Por otro lado, procesos de digestión artificial han permitido reducir 10.000 veces la capacidad enlazante de IgE. La hidrólisis enzimática de glicinina y $\beta$-conglicinina con tripsina y pepsina ha mostrado dependencia del $\mathrm{pH}$, sin embargo, la capacidad enlazante de IgG no se ha logrado eliminar por completo ${ }^{107}$. Mientras que la combinación de calentamiento a $100{ }^{\circ} \mathrm{C}$ e hidrólisis enzimática con pepsina resultó en una reducción de la capacidad enlazante de lgE a niveles no detectables ${ }^{108}$. De otra parte, la fermentación de semillas y harina de soja evaluada en suero humano ha permitido una reducción de la capacidad enlazante de IgE entre 65 y $99 \%{ }^{109}$. Existen otros hallazgos de reducción de alergenecidad reportados en la literatura, pero su efecto sobre anticuerpos humanos no se ha determinado aún.

Usualmente, pacientes alérgicos al trigo o intolerantes al gluten consumen la quinoa como sustituto de los cereales. Sin embargo, pocos han sido los hallazgos que confirman reacciones alérgicas. La literatura describe casos muy puntuales o aislados asociados a la principal proteína de almacenamiento termoestable tipo globulinas, chenopodina ${ }^{110,111}$.

La industria alimentaria también podría recurrir a procesamientos que no impliquen efectos térmicos a través de procesos con alta presión hidrostática, incidencia de luz UV o caída de presión controlada. Se han detectado reducciones de hasta un $44 \%$ en la capacidad enlazante de lgG y lgE en extractos de soja descascarillados y desengrasados ${ }^{112,113}$.

Un campo ya explorado es el desarrollo de materiales resistentes biodegradables útiles en el empaque y conservación de los alimentos a partir de las harinas ${ }^{114,115}$. Finalmente, un campo que aún está por explorar en la industria alimentaria es la potenciación de compuestos bioactivos como los fitoecdisteroides con promisorios beneficios para diabéticos ${ }^{116}$, las isoflavonas asociadas a la reducción de síntomas de osteoporosis ${ }^{98}$ y los glucósidos flavonoides por sus interesantes aplicaciones como antioxidantes. Su identificación, incorporación como ingredientes y conservación tras procesos tecnológicos típicos, especialmente en el caso de la quinoa, continúan siendo objetos de investigación para el desarrollo de alimentos funcionales.

\section{CONCLUSIONES}

La quinoa resulta ser un cultivo menos sensible a la salinidad, al estrés por la sequía que la soja y a las heladas; $\sin$ embargo, son parámetros que se deben establecer puntualmente para cada variedad. Por otro lado, la cosecha de la soja se lleva a cabo casi en la mitad del tiempo que requiere la quinoa y genera mayores rendimientos. Respecto a la composición, ambas semillas son fuentes equiparables de proteínas y aminoácidos esenciales, con similares porcentajes de digestibilidad y ligeras diferencias en el contenido de minerales. Se destaca un mayor contenido de Ca y biodisponibilidad en la quinoa. Los niveles de vitaminas no suplen los requerimientos mínimos, pero son mayores que los contenidos en otros alimentos de consumo frecuente como el arroz, cebada y trigo, por lo que la investigación debe considerar tecnologías de procesamiento que permitan conservarlos. Además, tanto la quinoa como la soja poseen valiosas proporciones de compuestos bioactivos como antioxidantes e isoflavonas, y bajos niveles de prolaminas, que favorecen y promueven su uso en la industria alimentaria para suplir la demanda de la población por alimentos funcionales y/o "libres de" de bajo costo y fácil acceso. Así mismo, estos productos alimenticios constituyen importantes alternativas para la implementación de políticas y planes de desarrollo gubernamentales, principalmente en los países en desarroIlo, dirigidas a reducir los latentes índices de malnutrición.

\section{AGRADECIMIENTOS - FINANCIACIÓN}

Los autores agradecen a la Vicerrectoría de Investigaciones de la Universidad del Cauca, Colombia, por financiar el proyecto VRI-4378 en el cual se enmarcó esta revisión. Además, Ortega y Ahumada extienden su agradecimiento por la financiación del proyecto VRI-4346.

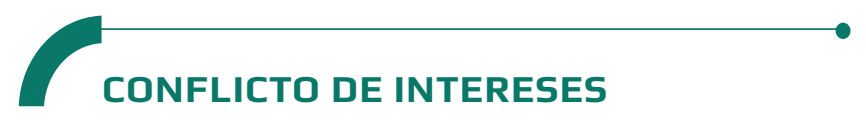

Los autores expresan que no hay conflictos de interés al redactar el manuscrito.

\section{REFERENCIAS}

(1) Organización de las Naciones Unidas para la Alimentación y la Agricultura. La FAO y los 17 Objetivos de Desarrollo Sostenible. FAO; 2015.

(2) Oficina Regional de la FAO para América Latina y el Caribe (FAO/RLC), editor. La Quinua: Cultivo milenario para contribuir a la seguridad alimentaria mundial. Santiago, Chile: FAO; 2011. 
(3) Kozioł MJ. Chemical composition and nutritional evaluation of quinoa (Chenopodium quinoa Willd.). J Food Compos Anal. 1992; 5(1): 35-68.

(4) de Luna A. Valor Nutritivo de la Proteína de Soya. Invest Cienc. 2006; 14(36): 29-34.

(5) Vlahović B, Ilin S, Puškarić A. Status and Perspectives of Soybean Production Worldwide and in the Republic of Serbia. Econ Insights Trends Chall. 2013; 65(1): 38-46.

(6) Organización de las Naciones Unidas para la Alimentación y la Agricultura. El estado mundial de la agricultura y la alimentación: Sistemas alimentarios para una mejor nutrición. Roma, Italia: FAO; 2013.

(7) Organización de las Naciones Unidas para la Alimentación y la Agricultura. La Reducción de la Pobreza y el Hambre: La Función Fundamental de la Financiación de la Alimentación, la Agricultura y el Desarrollo Rural. FAO; 2002.

(8) Soto JL, Hartwich F, Monge M, Ampuero L. ISNAR Division Discussion Paper 11 - Innovación en el Cultivo de Quinua en Bolivia: Efectos de la Interacción Social y de las Capacidades de Absorción de los Pequeños Productores. Washington, DC: International Food Policy Research Institute; 2006.

(9) Gras C. Los empresarios de la soja: cambios y continuidades en la fisonomía y composición interna de las empresas agropecuarias. Mundo Agrario. 2012; 12(24).

(10) Salcedo S, Sanches A, Coloma MJ. Capítulo 3 - Agricultura Familiar y Seguridad Alimentaria: el éxitoso caso del proyecto Forsandino. En: Salcedo S, Guzmán L, editores. Agricultura Familiar en América Latina y el Caribe: Recomendaciones de Política. Santiago, Chile: FAO; 2014. p. 57-77.

(11) Delgado Al, Palacios JH, Betancourt C. Evaluación de 16 genotipos de quinua dulce (Chenopodium quinoa Willd.) en el municipio de lles, Nariño (Colombia). Agron Colomb. 2009; 27(2): 159-67.

(12) Gabriel J, Luna N, Vargas A, Magne J, Angulo A, la Torre J, et al. Quinua de valle (Chenopodium quinoa Willd.): fuente valiosa de resistencia genética al mildiu (Peronospora farinosa Willd.). J Selva Andina Res Soc. 2012; 3(2): 27-44.

(13) López J, Timaran M, Betancourth C. Evaluación de 16 selecciones de quinua dulce (Chenopodium quinoa Willd.) en el municipio de Guaitarilla, Nariño. Rev Cienc Agr. 2012; 25(1 y 2): 130-49.

(14) Valencia-Chamorro SA. Quinoa. En: Caballero B, editor. Encyclopedia of Food Sciences and Nutrition. Second Edition. Oxford: Academic Press; 2003. p. 4895-902.

(15) Vega-Gálvez A, Miranda M, Vergara J, Uribe E, Puente L, Martínez EA. Nutrition facts and functional potential of quinoa (Chenopodium quinoa willd.), an ancient Andean grain: a review. J Sci Food Agric. 2010; 90(15): 2541-7.

(16) Wahli C. Quinua: Hacia su cultivo comercial. Quito, Ecuador: Latinreco S.A; 1990.

(17) Vasconcelos FS de, Vasconcelos ES de, Balan MG, Silvério L. Desenvolvimento e produtividade de quinoa semeada em diferentes datas no período safrinha. Rev Ciênc Agron. 2012; 43(3): 510-5.

(18) Fischer S, Wilckens R, Jara J, Aranda M. Controlled water stress to improve functional and nutritional quality in quinoa seed. Bol Latinoam Caribe Plant Med Aromat. 2013; 12(5): 457-68.

(19) Hellal FA, Abdelhamid MT. Nutrient management practices for enhancing soybean (Glycine max L.) production. Acta biolColomb. 2013; 18(2): 239-50.

(20) Tosquy OH, Esqueda VA, Durán A. Sistemas de siembra para soya de invierno en Veracruz, México. Agron Mesoam. 2006; 17(1): 47-53.

(21) Valencia R, Ligarreto GA. Mejoramiento genético de la soya (Glycine max [L.] Merril) para su cultivo en la altillanura colombiana: una visión conceptual prospectiva. Agron Colomb. 2010; 28(2): 155-63.

(22) Villalobos E, Camacho F. Desarrollo de variedades tropicales de soya para el consumo humano. Agron Mesoam. 2000; 11(2): 1-6.

(23) Vasconcelos IM, Campello CC, Oliveira JTA, Carvalho AFU, Souza DOB de, Maia FMM. Brazilian soybean Glycine max (L.) Merr. cultivars adapted to low latitude regions: seed composition and content of bioactive proteins. Rev bras Bot. 2006; 29(4): 617-25.

(24) Oliveira P de, Nascente AS, Kluthcouski J. Soybean growth and yield under cover crops. Rev Ceres. 2013; 60(2): 249-56.

(25) Jancurová M, Minarovičová L, Dandár A. Quinoa - a Review. Czech J Food Sci. 2009; 27(2): 71-9.

(26) Barbieri PA, Echeverría HE, Sainz HR, Martínez JP. Soybean and wheat response to lime in no-till Argentinean mollisols. Soil and Tillage Research. 2015; 152: 29-38.

(27) Cocozza C, Pulvento C, Lavini A, Riccardi M, d'Andria R, Tognetti R. Effects of Increasing Salinity Stress and Decreasing Water Availability on Ecophysiological Traits of Quinoa (Chenopodium quinoa Willd.) Grown in a Mediterranean-Type Agroecosystem. J Agron Crop Sci. 2013; 199(4): 229-40.

(28) Lavini A, Pulvento C, d'Andria R, Riccardi M, Choukr-Allah R, Belhabib O, et al. Quinoa's Potential in the Mediterranean Region. J Agron Crop Sci. 2014; 200(5): 344-60.

(29) Bustingorri C, Lavado RS. Soybean growth under stable versus peak salinity. Sci agric. 2011; 68(1): 102-8.

(30) Pulvento C, Riccardi M, Lavini A, D'andria R, Ragab R. Saltmed Model to Simulate Yield and Dry Matter for Quinoa Crop and Soil Moisture Content Under Different Irrigation Strategies in South Italy. Irrig and Drain. 2013; 62(2): 229-38.

(31) Pulvento C, Riccardi M, Lavini A, lafelice G, Marconi E, d'Andria $R$. Yield and quality characteristics of quinoa grown in open field under different saline and non-saline irrigation regimes. Journal of Agronomy and Crop Science. 2012; 198(4): 254-63.

(32) Peterson A, Murphy K. Tolerance of Lowland Quinoa Cultivars to Sodium Chloride and Sodium Sulfate Salinity. Crop Sci. 2015; 55: 331-8.

(33) Ghassemi-Golezani K, Taifeh-Noori M. Chapter 34 - Soybean Performance under Salinity Stress. En: Ng T-B, editor. Soybean - Biochemistry, Chemistry and Physiology. Rijeka, Croacia: InTech; 2011.

(34) Razzaghi F, Ahmadi SH, Jacobsen S-E, Jensen CR, Andersen MN. Effects of Salinity and Soil-Drying on Radiation Use Efficiency, Water Productivity and Yield of Quinoa (Chenopodium quinoa Willd.). J Agron Crop Sci. 2012; 198(3): 173-84.

(35) Jacobsen S-E, Monteros C, Corcuera L, Bravo LA, Christiansen $\mathrm{JL}$, Mujica A. Frost resistance mechanisms in quinoa (Chenopodium quinoa Willd.). Eur J Agron. 2007; 26(4): 471-5.

(36) Meyer DW, Badaruddin M. Frost tolerance of ten seedling legume species at four growth stages. Crop Sci. 2001; 41(6): 1838-42. 
(37) Jacobsen S-E, Monteros C, Christiansen JL, Bravo LA, Corcuera $\mathrm{L}$, Mujica A. Plant responses of quinoa (Chenopodium quinoa Willd.) to frost at various phenological stages. Eur ] Agron. 2005; 22(2): 131-9.

(38) de Bruin JL, Pedersen P. Effect of Row Spacing and Seeding Rate on Soybean Yield. Agron J. 2008; 100(3): 704-10.

(39) Spehar CR, Rocha JE da S. Effect of sowing density on plant growth and development of quinoa, genotype 4.5, in the Brazilian savannah highlands. Biosci J. 2009; 25(4): 53-8.

(40) Mujica A, Jacobsen S, Izquierdo J, Marathee J, editores. Quinoa (Chenopodium quinoa Willd.) ancestral cultivo andino, alimento del presente y futuro. Santiago, Chile: FAO, UNAPuno, CIP; 2001.

(41) DeWerff RP, Conley SP, Colquhoun JB, Davis VM. Can Soybean Seeding Rate Be Used as an Integrated Component of Herbicide Resistance Management? Weed Sci. 2014; 62(4): 625-36.

(42) Comai S, Bertazzo A, Bailoni L, Zancato M, Costa CVL, Allegri G. Protein and non-protein (free and protein-bound) tryptophan in legume seeds. Food Chem. 2007; 103(2): 657-61.

(43) James AT, Yang A. Interactions of protein content and globulin subunit composition of soybean proteins in relation to tofu gel properties. Food Chem. 2016; 194: 284-9.

(44) Nowak V, Du J, Charrondière UR. Assessment of the nutritional composition of quinoa (Chenopodium quinoa Willd.). Food Chem. 2016; 193: 47-54.

(45) Ferreira DS, Pallone JAL, Poppi RJ. Direct analysis of the main chemical constituents in Chenopodium quinoa grain using Fourier transform near-infrared spectroscopy. Food Control. 2015; 48: 91-5.

(46) Mäkinen OE, Zannini E, Koehler P, Arendt EK. Heat-denaturation and aggregation of quinoa (Chenopodium quinoa) globulins as affected by the $\mathrm{pH}$ value. Food Chemistry. 2016; 196: 17-24.

(47) de Vincenzi M, Silano M, Luchetti R, Carratù B, Boniglia C, Pogna NE. Agglutinating activity of alcohol-soluble proteins from quinoa seed flour in celiac disease. Plant Foods Hum Nutr. 1999; 54(2): 93-100.

(48) Magoshi J, Becker MA, Han Z, Nakamura S. Thermal properties of seed proteins. J Therm Anal Calorim. 2002; 70(3): 833-9.

(49) World Gastroenterology Organisation. Enfermedad celíaca [Internet]. WGO. 2012 [citado 16 de abril de 2016]. Disponible en: http://www.worldgastroenterology.org/guidelines/ global-guidelines/celiac-disease/celiac-disease-spanish

(50) Zevallos VF, Ellis HJ, Suligoj T, Herencia LI, Ciclitira PJ. Variable activation of immune response by quinoa (Chenopodium quinoa Willd.) prolamins in celiac disease. Am J Clin Nutr. 2012; 96(2): 337-44.

(51) Boye J, Wijesinha-Bettoni R, Burlingame B. Protein quality evaluation twenty years after the introduction of the protein digestibility corrected amino acid score method. $\mathrm{Br}$ ] Nutr. 2012; 108(Suppl 2): S183-211.

(52) Ahamed NT, Singhal RS, Kulkarni PR, Pal M. A LesserKnown Grain, Chenopodium quinoa: Review of the Chemical Composition of its Edible Parts. Food Nutr Bull. 1998; 19(1): 61-70.

(53) Berk Z. Technology of production of edible flours and protein products from soybeans. FAO Agricultural Services Bulletin No. 97. Roma, Italia: FAO; 1992.
(54) Bhat R, Sridhar KR. Nutritional quality evaluation of electron beam-irradiated lotus (Nelumbo nucifera) seeds. Food Chem. 2008; 107(1): 174-84.

(55) Carrera CS, Reynoso CM, Funes GJ, Martínez M], Dardanelli J, Resnik SL. Amino acid composition of soybean seeds as affected by climatic variables. Pesq Agropec Bras. 2011; 46(12): 1579-87.

(56) Joint FAO/WHO Expert Consultation on Protein Quality Evaluation (1989: Bethesda, Maryland), World Health Organization, Food and Agriculture Organization of the United Nations. Protein quality evaluation: report of the Joint FAO/WHO Expert Consultation. FAO Food Nutr Pap. 1991; 51.

(57) Chaparro DC, Pismag RY, Elizalde A, Vivas NJ, Erazo CA. Efecto de la germinación sobre el contenido y digestibilidad de proteína en semillas de amaranto, quinua, soya y guandul. Rev Bio Agro. 2010; 8(1): 35-42.

(58) Peiretti PG, Gai F, Tassone S. Fatty acid profile and nutritive value of quinoa (Chenopodium quinoa Willd.) seeds and plants at different growth stages. Anim Feed Sci Tech. 2013; 183(1): 56-61.

(59) Suárez MM, Kizlansky A, López LB. Evaluación de la calidad de las proteínas en los alimentos calculando el escore de aminoácidos corregido por digestibilidad. Nutr Hosp. 2006; 21(1): 47-51.

(60) Mota C, Santos M, Mauro R, Samman N, Matos AS, Torres D, et al. Protein content and amino acids profile of pseudocereals. Food Chem. 2016; 193: 55-61.

(61) Gutiérrez-Espinosa MC, Vásquez-Torres W. Digestibilidad de Glicine max L, soya, en juveniles de cachama blanca Piaractus brachypomus Cuvier 1818. Orinoquia. 2008; 12(2): 141-8.

(62) Miranda M, Vega-Gálvez A, Martínez EA, López J, Marín R, Aranda $M$, et al. Influence of contrasting environments on seed composition of two quinoa genotypes: nutritional and functional properties. Chilean J Agric Res. 2013; 73(2): 108-16.

(63) Miranda M, Vega-Gálvez A, Quispe-Fuentes I, Rodríguez MJ, Maureira H, Martínez EA. Aspectos Nutricionales de Seis Ecotipos de Quínoa (Chenopodium quinoa Willd.) de Tres Zonas Geográficas de Chile. Chilean J Agric Res. 2012; 72(2): 175-81.

(64) Wang M, Fu Y, Liu H. Nutritional quality and ions uptake to PTNDS in soybeans. Food Chem. 2016; 192: 750-9.

(65) Boza López J. Valor nutritivo de las leguminosas grano en la alimentación humana y animal. An R Acad Cienc Vet. 1991; 3: 71-96.

(66) Repo-Carrasco R, Espinoza C, Jacobsen S-E. Nutritional Value and Use of the Andean Crops Quinoa (Chenopodium quinoa) and Kañiwa (Chenopodium pallidicaule). Food Reviews International. 2003; 19(1-2): 179-89.

(67) Ferreira DS, Poppi RJ, Lima JA. Evaluation of dietary fiber of Brazilian soybean (Glycine max) using near-infrared spectroscopy and chemometrics. J Cereal Sci. 2015; 64: 43-7.

(68) Ruales J, Nair BM. Properties of starch and dietary fibre in raw and processed quinoa (Chenopodium quinoa Willd.) seeds. Plant Food Hum Nutr. 1994; 45(3): 223-46.

(69) Tang $Y$, Li X, Chen PX, Zhang B, Hernandez M, Zhang $H$, et al. Characterisation of fatty acid, carotenoid, tocopherol/ tocotrienol compositions and antioxidant activities in seeds of three Chenopodium quinoa Willd. genotypes. Food Chem. 2015; 174: 502-8. 
(70) Ruales J, Nair BM. Content of fat, vitamins and minerals in quinoa (Chenopodium quinoa Willd.) seeds. Food Chem. 1993; 48(2): 131-6.

(71) van Ee JH. Soy constituents: modes of action in low-density lipoprotein management. Nutr Rev. 2009; 67(4): 222-34.

(72) Kramer CM, Launis KL, Traber MG, Ward DP. Vitamin E levels in soybean (Glycine max (L.) Merr.) expressing a p-hydroxyphenylpyruvate gene from oat (Avena sativa L.). J Agric Food Chem. 2014; 62(15): 3453-7.

(73) Pinheiro-Sant'ana HM, Guinazi M, Oliveira D da S, Della Lucia CM, Reis B de L, Brandão SCC. Method for simultaneous analysis of eight vitamin $E$ isomers in various foods by high performance liquid chromatography and fluorescence detection. J Chromatogr A. 2011; 1218(47): 8496-502.

(74) Ortega-Bonilla RA, Chito-Trujillo DM. Prevalencia de sobrepeso y obesidad en escolares de una comunidad rural Colombiana. Rev Esp Nutr Hum Diet. 2015; 19(4): 212-20.

(75) Ortega-Bonilla RA, Chito-Trujillo DM. Valoración del estado nutricional de la población escolar del municipio de Argelia, Colombia. Rev Salud Pública. 2014; 16(4): 547-59.

(76) Ranhotra GS, Gelroth JA, Glaser BK, Lorenz KJ, Johnson DL. Composition and protein nutritional quality of quinoa. Cereal Chem. 1993; 70: 303-5

(77) Blanco T, Alvarado-Ortiz C, Muñoz AM, Muñoz C. Evaluación de la composición nutricional de la quinua (Chenopodium quinoa Willd.) procedente de los departamentos de Junín, Puno, Apurímac, Cusco y Ancash. Horiz Méd. 2002; 2(1/2): 27-34.

(78) Lazarte CE, Carlsson N-G, Almgren A, Sandberg A-S, Granfeldt Y. Phytate, zinc, iron and calcium content of common Bolivian food, and implications for mineral bioavailability. ] Food Compos Anal. 2015; 39: 111-9.

(79) Miranda M, Vega-Gálvez A, López J, Parada G, Sanders $M$, Aranda $M$, et al. Impact of air-drying temperature on nutritional properties, total phenolic content and antioxidant capacity of quinoa seeds (Chenopodium quinoa Willd.). Ind Crop Prod. 2010; 32(3): 258-63.

(80) Nascimento AC, Mota C, Coelho I, Gueifão S, Santos M, Matos AS, et al. Characterisation of nutrient profile of quinoa (Chenopodium quinoa), amaranth (Amaranthus caudatus), and purple corn (Zea mays L.) consumed in the North of Argentina: proximates, minerals and trace elements. Food Chem. 2014; 148: 420-6.

(81) Lebiedzińska A, Szefer P. Vitamins B in grain and cereal-grain food, soy-products and seeds. Food Chem. 2006; 95(1): 116-22.

(82) Plaza L, de Ancos B, Cano MP. Nutritional and health-related compounds in sprouts and seeds of soybean (Glycine max), wheat (Triticum aestivum L.) and alfalfa (Medicago sativa) treated by a new drying method. Eur Food Res Technol. 2003; 216: 138-44.

(83) Ridner E, Sociedad Argentina de Nutrición. Soja: propiedades nutricionales y su impacto en la salud. Buenos Aires, Argentina: Sociedad Argentina de Nutrición; 2006.

(84) World Health Organization, Food and Agriculture Organization of the United Nations. Vitamin and Mineral Requirements in Human Nutrition. 2nd Ed. China: World Health Organization; 2004.

(85) Gobernación del Cauca. PANES [Internet]. Gobernación del Cauca. [citado 16 de diciembre de 2015]. Disponible en: http://www.cauca.gov.co/etiquetas/panes

(86) Asociación de la Cadena de la Soja Argentina. ACSOJA
[Internet]. ACSOJA. 2012 [citado 18 de diciembre de 2015]. Disponible en: http://www.acsoja.org.ar/

(87) Ando H, Chen Y-C, Tang H, Shimizu M, Watanabe K, Mitsunaga T. Food Components in Fractions of Quinoa Seed. Food Sci Technol Res. 2002; 8(1): 80-4.

(88) Humer E, Schedle K. Fermentation of food and feed: A technology for efficient utilization of macro and trace elements in monogastrics. J Trace Elem Med Biol. 2016; 37: 69-77.

(89) Gehan AEE, Amin AY. Assessment level of some antinutritional and nutritional factors in some Egyptian cultivated soybean and barley. Res J Agric Biol Sci. 2010; 6(4): 481-6.

(90) Kumari S, Krishnan V, Jolly M, Sachdev A. Reduction in phytate levels and $\mathrm{HCl}$-extractability of divalent cations in soybean (Glycine max L.) during soaking and germination. Ind J Plant Physiol. 2015; 20(1): 44-9.

(91) Sharma S, Kaur M, Goyal R, Gill BS. Physical characteristics and nutritional composition of some new soybean (Glycine max (L.) Merrill) genotypes. J Food Sci Technol. 2014; 51(3): 551-7.

(92) Valencia S, Svanberg U, Sandberg AS, Ruales J. Processing of quinoa (Chenopodium quinoa Willd.): effects on in vitro iron availability and phytate hydrolysis. Int ] Food Sci Nutr. 1999; 50: 203-11.

(93) Moura NC, Canniatti-Brazaca SG, Souza MC, Dias CTS. Composição de cultivares de soja submetida a diferentes tratamentos térmicos. Alim Nutr. 2007; 18(2): 151-60.

(94) Meriles JM, Guzmán CA, Maestri DM. Lipoxygenase-1 Activity of Soybean Genotypes Grown in Argentina. Molecules. 2000; 5(3): 475-8.

(95) Gómez-Caravaca AM, lafelice G, Verardo V, Marconi E, Caboni MF. Influence of pearling process on phenolic and saponin content in quinoa (Chenopodium quinoa Willd.). Food Chem. 2014; 157: 174-8

(96) Shiraiwa M, Harada K, Okubo K. Composition and Content of Saponins in Soybean Seed According to Variety, Cultivation Year and Maturity. Agric Biol Chem. 1991; 55(2): 323-31.

(97) Quicazán M, Caicedo L. Inactivación del inhibidor de tripsina durante el tratamiento térmico de bebidas de soya. Vitae. 2012; 19(Supl. 1): S337-9.

(98) Lutz M, Martínez A, Martínez EA. Daidzein and Genistein contents in seeds of quinoa (Chenopodium quinoa Willd.) from local ecotypes grown in arid Chile. Ind Crop Prod. 2013; 49: $117-21$.

(99) Liggins J, Mulligan A, Runswick S, Bingham SA. Daidzein and genistein content of cereals. Eur J Clin Nutr. 2002; 56(10): 961-6.

(100) Jellen EN, Maughan PJ, Bertero D, Munir H. Chapter 8: Prospects for quinoa (Chenopodium quinoa Willd.) improvement through biotechnology. En: Jain SM, Dutta S, editores. Biotechnology of Neglected and Underutilized Crops. Dordrecht, Países Bajos: Springer Netherlands; 2013. p. 173-201.

(101) Leguizamón A. Modifying Argentina: GM soy and socioenvironmental change. Geoforum. 2014; 53: 149-60.

(102) Organización de las Naciones Unidas para la Alimentación y la Agricultura. Agricultura mundial: hacia los años 2015/2030 Informe resumido. Roma, Italia: FAO; 2002.

(103) Verhoeckx KCM, Vissers YM, Baumert JL, Faludi R, Feys M, Flanagan $S$, et al. Food processing and allergenicity. Food Chem Toxicol. 2015; 80: 223-40. 
(104) Holzhauser T, Wackermann O, Ballmer-Weber BK, BindslevJensen C, Scibilia J, Perono-Garoffo L, et al. Soybean (Glycine max) allergy in Europe: Gly $\mathrm{m} 5$ (beta-conglycinin) and Gly $\mathrm{m} 6$ (glycinin) are potential diagnostic markers for severe allergic reactions to soy. J Allergy Clin Immunol. 2009; 123(2): 452-8.

(105) Ebisawa M, Brostedt P, Sjölander S, Sato S, Borres MP, Ito K. Gly $\mathrm{m} 2 \mathrm{~S}$ albumin is a major allergen with a high diagnostic value in soybean-allergic children. J Allergy Clin Immunol. 2013; 132(4): 976-978.e1-5.

(106) Gomaa A, Boye Jl. Impact of thermal processing time and cookie size on the detection of casein, egg, gluten and soy allergens in food. Food Res Int. 2013; 52(2): 483-9.

(107) Tsumura K. Improvement of the Physicochemical Properties of Soybean Proteins by Enzymatic Hydrolysis. Food Sci Technol Res. 2009; 15(4): 381-8.

(108)van Boxtel EL, van den Broek LAM, Koppelman SJ, Gruppen $H$. Legumin allergens from peanuts and soybeans: effects of denaturation and aggregation on allergenicity. Mol Nutr Food Res. 2008; 52(6): 674-82.

(109) Frias J, Song YS, Martínez-Villaluenga C, Gonzalez E, VidalValverde $C$. Fermented soyabean products as hypoallergenic food. P Nutr Soc. 2008; 67(OCE): E39.

(110) Astier C, Moneret-Vautrin D-A, Puillandre E, Bihain BE. First case report of anaphylaxis to quinoa, a novel food in France. Allergy. 2009; 64(5): 819-20.
(111) Konishi Y. Nutritional Characteristics of Pseudocereal Amaranth and Quinoa: Alternative Foodstuff for Patients with Food Allergy. J Jpn Soc Nutr Food Sci. 2002; 55(5): 299-302.

(112) Yang WW, Chung S-Y, Ajayi O, Krishnamurthy K, Konan K, Goodrich-Schneider R. Use of Pulsed Ultraviolet Light to Reduce the Allergenic Potency of Soybean Extracts. Int J Food Eng. 2010; 6(3): 1-12.

(113) Takács K, Guillamon E, Martin M, Cuadrado C, Burbano C, Muzquiz $M$, et al. Study of the effect of instant controlled pressure drop (DIC) treatment on IgE-reactive legume-protein patterns by electrophoresis and immunoblot. Food Agr Inmunol. 2014; 25(2): 173-85.

(114) Pagno CH, Kug TV, Costa TMH, de Oliveira A, Flores SH. Physical and antimicrobial properties of quinoa flour-based films incorporated with essential oil. J Appl Polym Sci. 2016; 133(16): 43311.

(115) Abugoch L, Tapia C, Plasencia D, Pastor A, Castro-Mandujano $O$, López $L$, et al. Shelf-life of fresh blueberries coated with quinoa protein/chitosan/sunflower oil edible film. J Sci Food Agric. 2016; 96(2): 619-26.

(116) Graf BL, Poulev A, Kuhn P, Grace MH, Lila MA, Raskin I. Quinoa seeds leach phytoecdysteroids and other compounds with anti-diabetic properties. Food Chem. 2014; 163: 178-85. 